\title{
Characterization of Calcium-Mediated Intracellular and Intercellular Signaling in the rMC-1 Glial Cell Line
}

\author{
Diana Yu, ${ }^{1}$ Marius Buibas, ${ }^{1}$ Siu-Kei Chow, ${ }^{1}$ Ian Y. Lee, ${ }^{1}$ Zakary Singer, ${ }^{1}$ and Gabriel A. Silva ${ }^{1,2,3,4}$ \\ ${ }^{1}$ Department of Bioengineering, University of California, San Diego, La Jolla, CA, USA; ${ }^{2}$ Department of Ophthalmology, \\ University of California, San Diego, La Jolla, CA, USA; ${ }^{3}$ Neurosciences Program, University of California, San Diego, \\ La Jolla, CA, USA; and ${ }^{4}$ Jacobs Retina Center, University of California, San Diego, 9415 Campus Point Drive, \\ La Jolla, CA 92037-0946, USA
}

(Received 9 October 2008; accepted 8 December 2008; published online 24 December 2008)

\begin{abstract}
Retinal Müller glial cells, in addition to providing homeostatic support to retinal neurons, have been shown to engage in modulation of neuronal activity and regulate vasomotor responses in the retina, among other functions. Calcium-mediated signaling in Müller cells has been implicated to play a significant role in the intracellular and intercellular interactions necessary to carry out these functions. Although the basic molecular mechanisms of calcium signaling in Müller cells have been described, the dynamics of calcium responses in Müller cells have not been fully explored. Here, we provide a quantitative characterization of calcium signaling in an in vitro model of Müller cell signaling using the rMC-1 cell line, a well-established line developed from rat Müller cells. rMC-1 cells displayed robust intracellular calcium transients and the capacity to support calcium transient-mediated intercellular calcium waves with signaling dynamics similar to that reported for Müller cells in in situ retinal preparations. Furthermore, pharmacological perturbations of intracellular calcium transients with thapsigargin and intercellular calcium waves with purinergic receptor antagonists and gap junction blockers (PPADS and FFA, respectively) suggest that the molecular mechanisms that underlie calcium signaling in $\mathrm{rMC}-1$ cells has been conserved with those of Müller cells. This model provides a robust in vitro system for investigating specific mechanistic hypotheses of intra- and intercellular calcium signaling in Müller cells.
\end{abstract}

Keywords-Glial cells, Müller cells, Calcium signaling, Calcium dynamics, Retina.

\section{INTRODUCTION}

Müller cells are the primary macroglial cell type of the neural sensory retina and have diverse functions in both health and disease. The classical role of these cells

Address correspondence to Gabriel A. Silva, Jacobs Retina Center, University of California, San Diego, 9415 Campus Point Drive, La Jolla, CA 92037-0946, USA. Electronic mail: gsilva@ucsd. edu is providing homeostatic support to retinal neurons, ${ }^{4}$ although a number of other functions including modulating neuronal activity via bi-directional communication with neurons in the inner nuclear layer, ${ }^{2,4,35-37}$ regulating vasomotor responses in the retina, ${ }^{15,29,50}$ and contributing to degenerative retinal pathologies through reactive gliosis have been proposed., ${ }^{3,18}$ Underlying the bi-directional signaling of Müller glia with neurons and vascular regulation are calcium changes that mediate intra- and intercellular signaling processes. ${ }^{29}$ Müller cells in in situ retinal and eye cup preparations have been shown to generate transient increases in intracellular calcium both spontaneously $^{1,45}$ and in response to light stimulation, ${ }^{37}$ with frequencies and durations comparable to those observed for astrocytes in brain slices ${ }^{33,40}$ and in vivo. ${ }^{16}$ Activation of metabotropic purinergic $\mathrm{P} 2 \mathrm{Y}$ receptors by extracellular adenosine $5^{\prime}$-triphosphate (ATP) leading to the formation of inosital triphosphate $\left(\mathrm{IP}_{3}\right)$ by phospholipase $\mathrm{C}$ (PLC), and $\mathrm{IP}_{3}$-dependent calcium release from intracellular stores have been implicated as key steps in the generation of calcium transients in vitro ${ }^{20,25}$ and in situ, ${ }^{23,25,34,37,55}$ although there is also evidence for activation of ionotropic purinergic receptors (i.e., $\mathrm{P} 2 \mathrm{X}_{7}$ ) that augment the calcium increase via influx from the extracellular milieu. ${ }^{5,39}$ Stimulation of in situ preparations with 488-nm light flashes has been shown to increase neuronal activity that correlates with an increased frequency of calcium transients in Müller cells. ${ }^{37}$ Light-evoked calcium responses have been shown to be blocked by suramin, a purinergic antagonist, and apyrase, which hydrolyzes ATP, providing support for an ATP-dependent mechanism. Interestingly, tetrodotoxin (TTX) is also able to block light-induced calcium responses in Müller cells, suggesting that amacrine and ganglion cells (retinal neurons that generate action potentials) may be necessary for light-evoked signaling to Müller cells. ${ }^{37}$ Conversely, signaling from Müller cells to 
neurons may also be mediated by calcium changes. It has been suggested that calcium increases in Müller cells mediate the release of ATP that, once hydrolyzed to adenosine by ecto-nucleotidases, induce hyperpolarizations in retinal ganglion cells by activating $\mathrm{A}_{15}$ adenosine receptors that open potassium channels. ${ }^{35}$ However, the details of this calcium-dependent ATP release require further investigation.

Calcium signaling in Müller cells has also been implicated to play an important role in pathology. Specifically, upregulated intracellular calcium responses have been associated with gliosis of Müller cells in retinal detachment and proliferative vitreoretinopathy (PVR). ${ }^{3,18,56}$ Müller cell endfeet in acutely isolated porcine retinal wholemounts display increased calcium responses to ATP stimulation one to three days following experimental rhegmatogenous detachment, along with increased expression of $\mathrm{P}_{2} \mathrm{Y}_{1}$ and $\mathrm{P}_{2} \mathrm{Y}_{2}$ receptors. Furthermore, this increase in calcium sensitivity extended to Müller cells beyond the region of detachment; potentially caused by alterations in the functional state of $\mathrm{P} 2$ receptors or resensitization of receptors by soluble growth factors released during pathology. ${ }^{18,58}$ Intracellular calcium increases via activation of metabotropic and ionotropic $\mathrm{P} 2$ receptors by extracellular ATP (as observed in retinal pathology) have also been shown to stimulate DNA synthesis and cell proliferation in primary Müller cells ${ }^{30,31,39}$ and are implicated as a potential mechanism for increased glial mitogenic activity in PVR. ${ }^{5,18}$ Finally, adenosine, the degradation product of ATP, has also been found at elevated concentrations under pathological conditions such as retinal hypoxia, ${ }^{43}$ and has been shown to potentiate increased Müller calcium transients in response to light stimulation. ${ }^{37}$

An intriguing but controversial observation made in in situ and in vitro experiments is the capability of Müller cells to support intercellular calcium waves mediated by intracellular calcium transients. ${ }^{1,34,37,38}$ Stimulation of Müller cells and retinal astrocytes in acutely isolated retina and eye cups using ATP ejection, mechanical, or electrical stimulation evoke calcium transients that propagate outward to adjacent glial cells as intercellular calcium waves. ${ }^{34,38}$ Intercellular signaling between Müller cells is mediated by ATP signaling via purinergic receptors, since waves have been shown to be blocked by the purinergic receptor antagonist, suramin. ${ }^{34}$ In addition, gap junction channels formed by homeotypic and heterotypic coupling of hemichannels involving connexin 43 have also been implicated in calcium transient-mediated intercellular signaling, presumably by allowing exchange of small secondary messengers (i.e., $\mathrm{Ca}$ and IP3). ${ }^{17,21,32,51,59}$ Although experimentally evoked calcium waves have been shown to participate in the modulation of neuronal activity and vasomotor responses, ${ }^{29}$ these observations are controversial because intercellular calcium waves in Müller cells have not been observed under physiological conditions in vivo, raising the issue of whether the in vitro and in situ observations may be an experimental artifact. ${ }^{37}$ Calcium transients observed in individual Müller cells of acutely isolated eye cups in response to 488-nm light stimulation were not seen to propagate through networks, ${ }^{37}$ although neither the physiological range of luminous stimuli nor physiologically realistic stimulation patterns have been fully explored, thus necessitating more detailed follow-up studies. However, the same paper did report intercellular calcium signaling between Müller cells under conditions that mimic neuropathology. ${ }^{37}$ In the presence of elevated adenosine, light stimulation sometimes produced a delayed calcium response in Müller cells that propagated into neighboring cells, ${ }^{37}$ suggesting a potential contribution of intercellular calcium waves to disease states in the neural retina.

Although the basic molecular mechanisms of calcium signaling in Müller cells have been described, the dynamics of calcium responses in Müller cells have not been fully explored. This is critical for investigating any physiological or pathophysiological roles calcium signaling may be playing. Here we provide a quantitative characterization of calcium signaling in an in vitro model using the rMC-1 cell line, a wellestablished line developed from rat Müller cells ${ }^{46}$ that has been used in numerous studies to investigate the cell biology of Müller cells and their contributions to pathology. ${ }^{10-12,19,26,46,48}$ The dynamics of individual intracellular calcium transients and intercellular calcium waves were analyzed in individual cells and networks of rMC-1-cells. Very similar to data from primary Müller cells in vitro and in situ, rMC-1 cells displayed robust intracellular calcium transients and the capacity to support calcium transient-mediated intercellular calcium waves. Furthermore, pharmacological experiments suggest that the molecular mechanisms that underlie calcium signaling in $\mathrm{rMC}-1$ cells are dependent on activation of purinergic receptors by extracellular ATP and, to a lesser extent $\mathrm{IP}_{3}$-mediated gap junctional signaling, similar to that described for Müller cells. Lastly, the dynamics of calcium signaling in rMC-1 cells are quantitatively very similar to in situ Müller cells in intact retinal preparations that preserve the local cytoarchitecture. Although in vitro systems are simplified representations of physiological conditions, the calcium signaling mechanisms in rMC-1 cells seem to have been conserved with respect to the known physiological mechanisms in Müller cells. And although rMC-1 cells differ significantly from their relatives in the retina in some respects (e.g., morphology, 
functional polarization, etc.), the results we provide in the present work as well as the data from others ${ }^{10-12,19,26,46,48}$ suggest that, on a molecular and cellular level, rMC-1 cells are a good model of Müller cells and can provide an opportunity to study these fundamental processes under controlled experimental conditions where the complexity of the physiology or pathophysiology may confound direct measurements.

\section{MATERIALS AND METHODS}

\section{Reagents and Cell Cultures}

rMC-1 Müller cells (originally obtained courtesy of Dr. Vijay Sarthy, Northwestern University, Chicago, IL) were passaged four to five times to expand them from frozen stocks. All experiments were performed one day after recovered cells were seeded on P35 glassbottom Petri dishes (MatTek Corp., Ashland, MA) at $\sim 200,000$ cells $/ \mathrm{cm}^{2}$ incubated in culture media (high glucose Dulbecco's Modified Eagle's Medium (DMEM) supplemented with $10 \%$ fetal bovine serum (FBS), $2 \mathrm{mM}$ L-glutamine, and 1\% (v/v) Pen/Strep) at $37^{\circ} \mathrm{C}$ and $5 \% \mathrm{CO}_{2}$. Cell cultures reached workable confluency $(>80 \%)$ overnight. Media changes, in which all media were replaced, were performed every two days. Unless otherwise stated, all reagents were obtained from Sigma (St. Louis, MO).

\section{Calcium Imaging}

rMC-1 cultures of $\sim 80 \%$ confluency were washed twice with Kreb-HEPES buffer (KHB) solution (10 mM HEPES, $4.2 \mathrm{mM} \mathrm{NaHCO}$, $10 \mathrm{mM}$ glucose, $1.18 \mathrm{mM}$ $\mathrm{MgSO}_{4}, 1.18 \mathrm{mM} \mathrm{KH} \mathrm{PO}_{4}, 4.69 \mathrm{mM} \mathrm{KCl}, 118 \mathrm{mM}$ $\mathrm{NaCl}, 1.29 \mathrm{mM} \mathrm{CaCl} 2, \mathrm{pH}$ 7.4) and incubated with $5 \mu \mathrm{M}$ Fluo-4AM in KHB for $1 \mathrm{~h}$ at room temperature. Excess dye was removed by washing twice with KHB and an additional incubation of $30 \mathrm{~min}$ at room temperature was done to equilibrate intracellular dye concentration and ensure complete intracellular esterification. Intracellular calcium transients were induced by the application of adenosine $5^{\prime}$-triphosphate (ATP) at a final concentration of $50 \mu \mathrm{M}$. A range of ATP stimulation concentrations were tested (from 1 to $500 \mu \mathrm{M}) ; 50 \mu \mathrm{M}$ was the lowest concentration of ATP capable of inducing intracellular calcium responses in rMC-1 cells. Additionally, this concentration of ATP $(50 \mu \mathrm{M})$ has been used extensively in published studies on calcium transients in primary Müller glia cultures and acute retinal preparations as an effective dose that does not seem to negatively affect the cells. ${ }^{34,38,58}$ The use of a similar stimulation condition allowed the direct comparison of data in other published work. Treatment of $\mathrm{rMC}-1$ cultures with thapsigargin $(1 \mu \mathrm{M})$ were done at room temperature for 20 min prior to addition of ATP. Intercellular calcium waves were initiated by a single mechanical stimulation delivered to a localized region of $1-3$ cells using a $0.5 \mu \mathrm{m}$ i.d. micropipette tip (WPI Inc., Sarasota, FL) mounted on a M325 Micrometer Slide Micromanipulator (WPI Inc., Sarasota, FL). Comparable data were obtained using pharmacological ATP stimulation, although it was harder to ensure that only a localized region was initially stimulated; therefore, only data and results for mechanical stimulations are presented. Treatment of rMC-1 cultures with pyridoxal phosphate-6-azophenyl-2', 4'-disulfonic acid (PPADS; $100 \mu \mathrm{M}$ ), flufenamic acid (FFA; $100 \mu \mathrm{M}), \operatorname{MRS} 2179(100 \mu \mathrm{M})$, and apyrase $(50 \mathrm{U} / \mathrm{mL})$ was done by incubation with the respective compounds during the de-esterification phase. We analyzed seven FFA-treated cultures; three PPADStreated cultures; three MRS2179-treated cultures; three apyrase-treated cultures; and compared them to the five untreated rMC-1 cultures.

Visualization of calcium indicator dye fluorescence was done using a 488-nm (FITC) filter on an Olympus IX81 inverted fluorescence confocal microscope (Olympus Optical, Tokyo, Japan) that included epifluoresence, confocal, phase, brightfield, and Hoffman differential interference contrast (DIC) modalities. Real-time movie recordings of intracellular calcium transients were acquired at $5 \mathrm{~Hz}$ for $500 \mathrm{~s}$ while intercellular calcium transient propagation was acquired at $16.3 \mathrm{~Hz}$ until dissipation of the waves using a Hamamatsu ORCA-ER digital camera (Hamamatsu Photonics K.K., Hamamatsu City, Japan) and ImagePro Plus data acquisition and morphometric software (version 5.1.0.20, Media Cybernetics, Inc., Silver Spring, MD).

\section{Quantification of Calcium Transients}

Using ImageJ, an open source morphometric application (http://rsbweb.nih.gov/ij/), the circle-select tool was modified to allow manual selection of individual cells on the $x y$-plane of each movie using circles of 4 pixels $(\sim 5 \mu \mathrm{m})$ in diameter. Each cell was considered as an individual region of interest (ROI). In building the ROI list for each movie, we traced cells in the frame in which they appeared brightest as a result of an activation event. By going through all the frames in a movie, we were able to catalog every cell in the field of view that participated in the propagation of signaling waves in the network for a given movie. An ImageJ plugin was used to calculate the average intensity for each ROI in each frame as well as the $x-y$ coordinates of its area centroids. All of this data was organized in matrix format for postprocessing analyses. Since the fluorescence intensity of Fluo-4 AM 
was proportional to calcium concentrations, changes in cytosolic calcium concentrations could be inferred from the fluorescence profile of individual cells.

For analysis of individual intracellular calcium transients, the data was processed to identify periods of sustained increases in fluorescence intensity. Due to the highly dynamic and cyclic nature of the intracellular calcium transients, an averaging filter of 15 frames was applied to reduce noise and a first-derivative filter was then used to identify significant and sustained increases in calcium (i.e., 15 or more consecutive frames with positive derivative values). We defined this as the rise phase of the intracellular calcium transients. For analysis of intercellular calcium waves, an averaging filter of five frames was applied to the data to reduce noise in the fluorescence signals. The change in fluorescence intensity normalized to the level of baseline fluorescence $(\Delta F / F)$ was taken to indicate the magnitude of calcium changes within rMC-1 cells. $\Delta F / F$ greater than two standard deviations from baseline and a decrease of fluorescence intensity to $10 \%$ of its peak value were used as criteria for fluorescence profiles of completed calcium transients (i.e., that had experienced both full activation and deactivation; see Fig. 3). Real-time recordings of calcium signaling in response to mechanical stimulations were assessed at both the network and individual cell level. All calculations and graphs were done using Matlab (Mathworks, Natick, MA).

\section{Immunocytochemistry}

Immunocytochemistry (ICC) was performed on rMC-1 cultures prepared identically to those used for calcium imaging. Cells were fixed in $4 \%$ paraformaldehyde (Electron Microscopy Sciences, Hatfield, PA) for $15 \mathrm{~min}$ and washed twice with physiologically buffered saline (PBS; Invitrogen, Carlsbad, CA). Cultures labeled for glial fibrillary acidic protein (GFAP) were permeabilized in $1 \% \mathrm{FBS}$ and $0.1 \%$ Triton X-100 (Fisher Scientific International, Hampton, NH) for $30 \mathrm{~min}$ before incubating with anti-GFAP primary antibody (1:50; Sigma, St. Louis, MO) while cultures labeled for $\mathrm{P}_{2} \mathrm{Y}_{1}$ receptor, $\mathrm{P}_{2} \mathrm{X}_{7}$ receptor, and connexin 43 were incubated with their respective primary antibodies at 1:25 (Invitrogen, San Francisco, CA), 1:10 (Sigma, St. Louis, MI), and 1:50 (Chemicon, Temecula, CA) dilutions, respectively, with $10 \%$ FBS in PBS for $2 \mathrm{~h}$. Routine negative controls for all conditions included the omission of the primary antibody and incubation with $10 \%$ FBS in PBS during the primary incubation step. For secondary antibody labeling, cells labeled for GFAP were incubated with tetramethylrhodamine isothiocyanate (TRITC) conjugated anti-mouse IgG (1:50; Sigma, St. Louis,
MO) while cells labeled for $\mathrm{P}_{2} \mathrm{Y}_{1} \mathrm{R}, \mathrm{P} 2 \mathrm{X}_{7} \mathrm{R}$, and $\mathrm{Cx} 43$ were incubated with fluorescein isothiocyanate (FITC) conjugated anti-rabbit IgG (1:50; Sigma St. Louis, MO). Following the ICC, all slides were mounted using Molecular Probes Prolong ${ }^{\circledR}$ Gold antifade reagent with DAPI (Eugene, OR).

\section{RESULTS}

\section{rMC-1 Cells Express Specific Markers for Glial Cells and Metabotropic Purinergic Receptors}

Qualitatively, rMC-1 cells show similar expression patterns to Müller cells for key proteins, both in our hands and in previous work. Immunocytochemical characterization of glial fibrillary acidic protein (GFAP) showed low levels of baseline expression (Fig. 1a, e), consistent with in vivo Müller cells which only express high levels of GFAP when they become reactive following injury. ${ }^{10,26}$ Antibody labeling of $\mathrm{P} 2 \mathrm{Y}_{1} \mathrm{R}$, a metabotropic purinergic receptor that is G-protein coupled to induce release of calcium from intracellular stores through the formation of inosital triphosphate $\left(\mathrm{IP}_{3}\right)$ by PLC, displayed a strong expression profile (Fig. 1b, f). In addition, we also obtained positive labeling for $\mathrm{P}_{2} \mathrm{X}_{7}$ receptors (Fig. 1c, g), demonstrating the presence of both ionotropic and metabotropic forms of purinergic receptors on rMC-1 cells, consistent with known mechanisms for the role of ATP in calcium signaling by Müller cells. ${ }^{5,39}$ Finally, there was also positive expression for the gap junctional protein connexin 43 (CX43; Fig. 1d, h), a subtype commonly expressed on primary Müller cells. ${ }^{21,59}$

\section{rMC-1 Cells Exhibited ATP-Induced Intracellular Calcium Transients}

Using real-time calcium-sensitive fluorescence imaging, we recorded intracellular calcium transients in rMC-1 cells at a low frequency in the absence of applied stimulation. Five 500-s real-time recordings were analyzed and showed that approximately $2 \%$ of the cells in culture produced intracellular calcium transients in buffer in the absence of applied stimulation; an average of $23.3 \pm 3.0$ calcium transients were observed in each movie at a rate of $1.67 \pm 0.71$ transients/signaling cell $/ 500 \mathrm{~s}$, with calcium elevations averaging $5.9 \pm 0.5 \mathrm{~s}$ in duration. Application of $50 \mu \mathrm{M}$ ATP significantly increased the number of intracellular calcium transients in rMC-1 cells to $482.8 \pm 241.5$ per movie $(p<0.01$, Fig. 2a). Furthermore, ATP-induced increases in calcium signaling were due to significant increases in the number of cells exhibiting intracellular calcium transients (from $2 \%$ to 

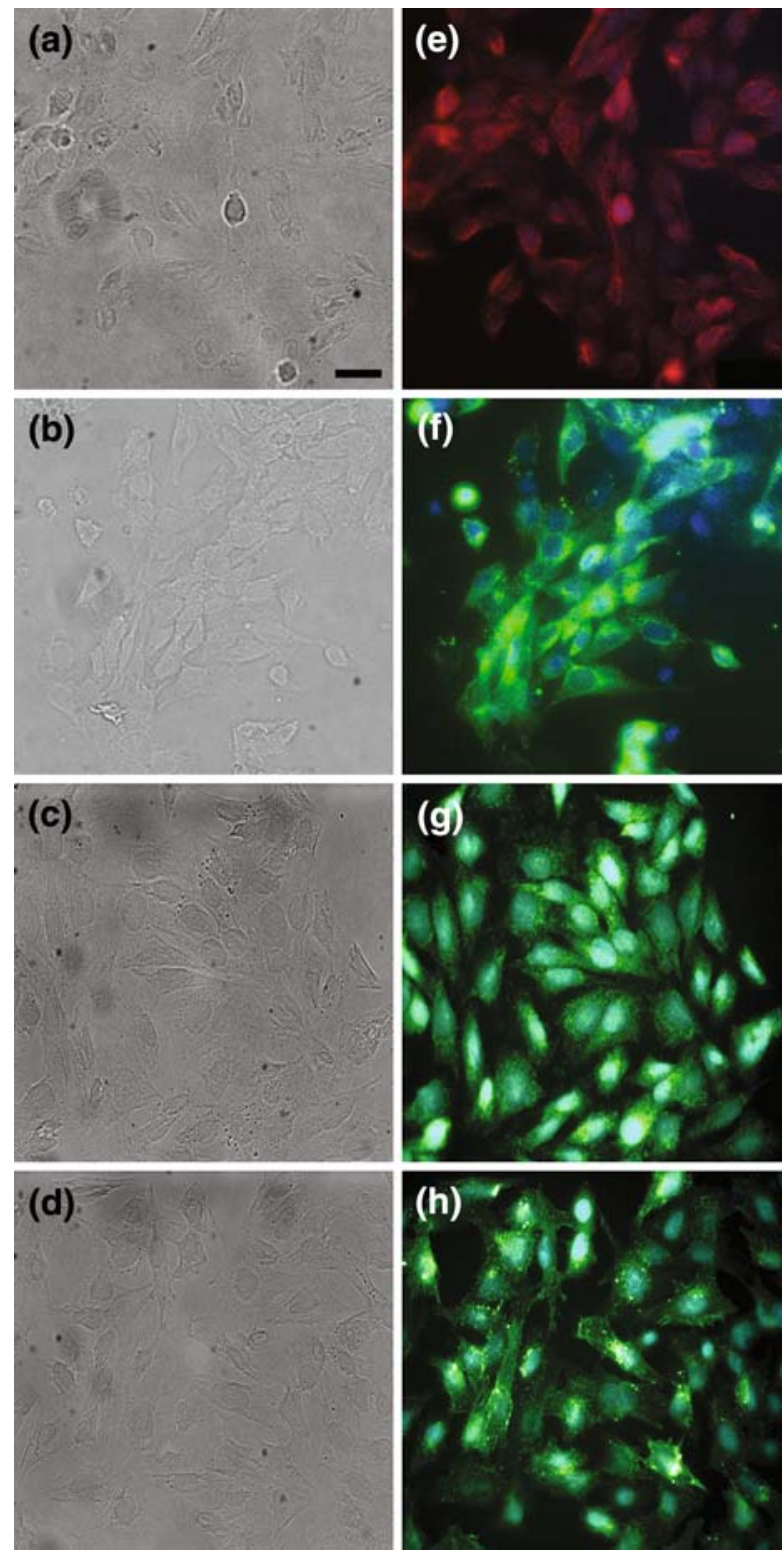

FIGURE 1. Immunocytochemistry of cultured rMC-1 Müller cells for GFAP, P2Y ${ }_{1} R, P_{2} X_{7} R$, and Cx43. (a-d) Phase-contrast micrographs of fluorescence images in $(e-h)$, respectively. (e-h) GFAP (e), P2Y ${ }_{1}$ R (e), P2X $X_{7} R(G)$, and Cx43 (H) immunoreactivity. All images were taken at $\times 400$, scale bar $=25 \mu \mathrm{m}$.

$31 \% ; p<0.01$, Fig. 2 b) rather than an increase in the frequency of calcium transients per signaling cell; which were $1.67 \pm 0.71$ and $1.74 \pm 0.25$ transients signaling cell $/ 500 \mathrm{~s}$ for controls and $50 \mu \mathrm{M}$ ATP, respectively, with no significant differences detected via the Student $t$-test. Interestingly, along with the increase in the number of intracellular calcium transients in ATP-treated cultures, we also observed a significant decrease in the average duration of calcium elevations to $3.4 \pm 0.6 \mathrm{~s}$ (Fig. 2c) following application of ATP. Quantification of the amplitude change $(\Delta F / F)$ of spontaneous vs. ATP-stimulated calcium transients showed an amplitude change of $31.8 \pm 5.7 \%$ for control cultures. Corresponding to the shorter duration of calcium elevations with the application of ATP, we observed a decrease in the average amplitude of calcium transients in comparison to controls (14.3 \pm $2.9 \%, p<0.01$, Fig. 2 d). Taken together, these results suggest that elevated extracellular ATP induced a higher number of faster calcium transients with smaller amplitudes vs. those of control conditions.

To probe the molecular mechanisms responsible for ATP-induced intracellular calcium transients in rMC-1 cells, we analyzed the effects of applying thapsigargin, a drug that depletes intracellular calcium stores via inhibition of the calcium ATPase pump on the endoplasmic reticulum (ER) ${ }^{53}$ Thapsigargin applied at a concentration of $1 \mu \mathrm{M}$ effectively blocked the increase in the number of intracellular calcium transients previously measured with $50 \mu \mathrm{M}$ extracellular ATP and rendered it comparable to that of control cultures (Fig. 2a). As before, our results indicated that this decreased incidence of calcium transients in the presence of elevated ATP (to $25.2 \pm 10.0$ transients per movie) was due to a significantly lower number of signaling rMC-1 cells in thapsigargin-treated cultures rather than changes in the frequency of transients per cell (which are $1.51 \pm 0.39,1.74 \pm 0.25$, and $1.51 \pm 0.57$ transients/signaling cell/500 s under $1 \mu \mathrm{M}$ thapsigargin, $50 \mu \mathrm{M}$ ATP, and $50 \mu \mathrm{M}$ ATP plus $1 \mu \mathrm{M}$ thapsigargin, respectively, with no significant differences detected by ANOVA). Furthermore, in the presence of thapsigargin, the amplitude and duration of calcium elevation in ATP-stimulated calcium transients were comparable to that of the control cultures $(23.7 \pm 8.0 \%$ and $5.15 \pm 1.1 \mathrm{~s})$.

Finally, to explore the possible ionotropic as well as the metabotropic components of the purinergic response, we tested ATP-enhanced responses in the presence of zero extracellular calcium and in the presence of specific inhibitors. In our hands, rMC-1 cells demonstrated an increase in intracellular calcium rather than calcium oscillations due to zero-extracellular calcium, thus implicating a role for extracellular calcium, potentially acting through ionotropic purinergic receptors; a return to calcium-containing buffer restored the ATP response. To explore the role of metabotropic purinergic receptor signaling, specifically the $\mathrm{P}_{2} \mathrm{Y}_{1}$ receptor, on ATP-potentiated intracellular calcium transients, we applied MRS2179 to specifically block this receptor. $100 \mu \mathrm{M}$ MRS2179 reduced the percentage of signaling cells from $31 \%$ to $11 \%$ in the presence of ATP as well as decreased the number of intracellular calcium transients approximately 50\% (to $246.2 \pm 182.8$ ), with no significant changes to the duration or amplitude of oscillations. Finally, 

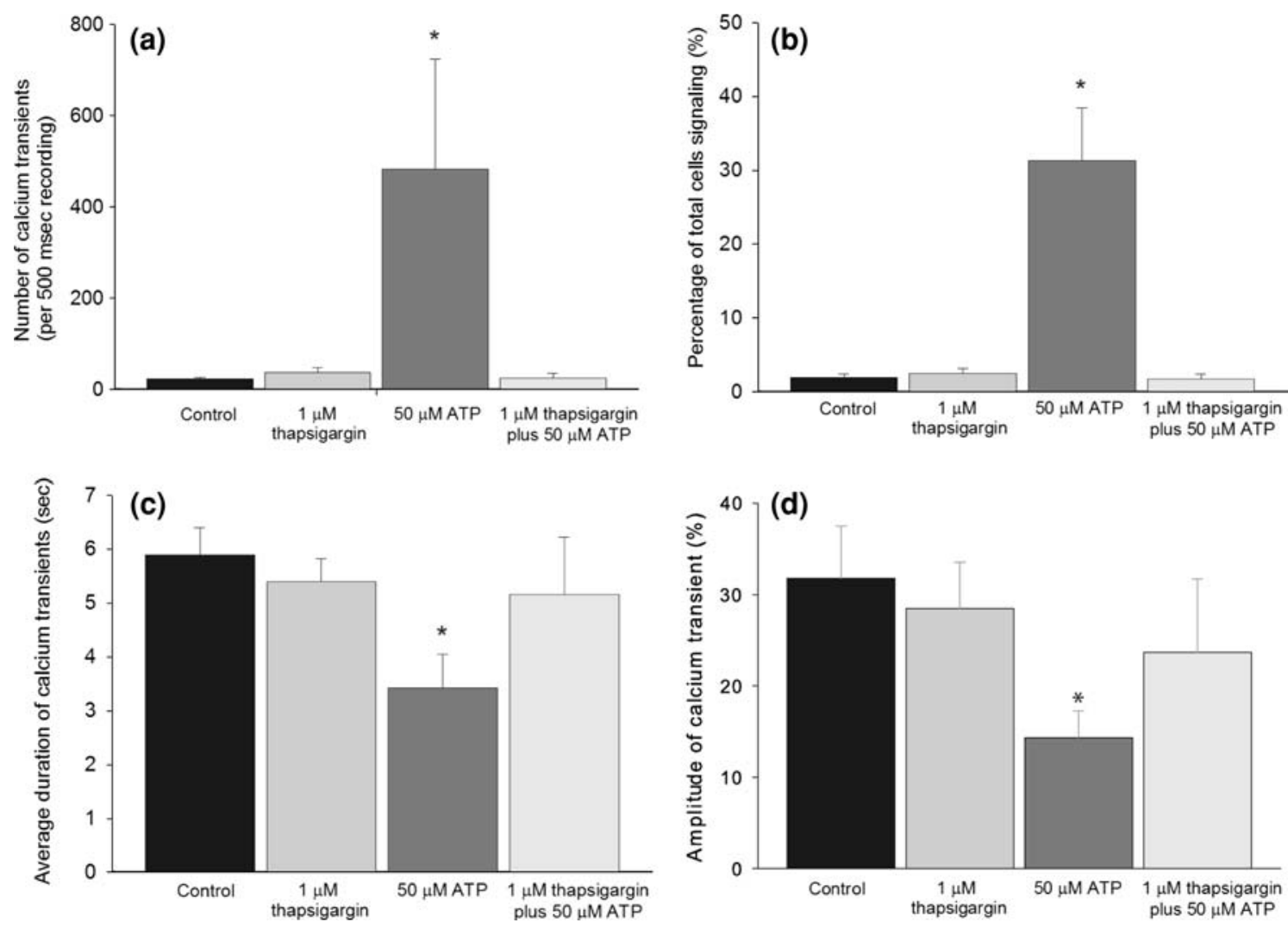

FIGURE 2. Intracellular calcium transients in untreated rMC-1 vs. cells treated with $50 \mu \mathrm{M}$ ATP, $1 \mu \mathrm{M}$ Thapsigargin, and $50 \mu \mathrm{M}$ ATP with $1 \mu \mathrm{M}$ Thapsigargin. Two-tailed Student $t$-tests were used to test for statistical significance. (a) The total number of calcium transients recorded during 500-s movies. (b) Percentage of cells that exhibited intracellular calcium transients during 500-s movies. (c) The average duration of calcium transients. (d) The average amplitude change of calcium transients calculated as $\Delta F / F$. ${ }^{\star} p<0.01,{ }^{*} p<0.001, n=7$.

application of $5 \mathrm{mM}$ PPADS, a broad-spectrum purinergic receptor antagonist, completely but reversibly inhibited ATP-stimulated calcium transients. The removal of PPADS restored the response of these cells to extracellular ATP.

\section{Intercellular Calcium Waves were Mediated by ATP and $I P_{3}$ and Displayed Specific Signaling Dynamics}

Localized stimulation of $\mathrm{rMC}-1$ cells induced a propagating wave of calcium transients that spread radially outward from an initial activated cell. For each recording, all cells participating in calcium waves were individually analyzed to quantitatively study the spatial and temporal properties of calcium transient propagation. To characterize the dynamics of intracellular calcium transient responses that underlie calcium waves, we measured: (1) activation time, the rise time from $10 \%$ to $90 \%$ of the peak amplitude, (2) deactivation time, the decay time from $90 \%$ to $10 \%$ of the peak amplitude, and (3) $\Delta F / F$, the percent change of maximum Fluo-4 fluorescence intensity with respect to the baseline resting state (Fig. 3a). We observed kinetic variations in calcium transient responses (Fig. 3b). Some cells displayed a rapid increase in cytosolic calcium (Fig. 3b, responses 1 and 3) while others had a gradual increase from baseline that preceded the main calcium rise (Fig. 3b, response 2). Additionally, some cells presented a smooth and rapid decrease (Fig. 3b, response 1), while others had a kinetically slower decrease (Fig. 3b, response 2) and displayed a secondary calcium hump (Fig. 3b, response 3). Combining five data sets $(100 \pm 20$ cells were analyzed per recording), the averaged values for activation and deactivation times were $3.87 \pm 0.62 \mathrm{~s}$ and $18.91 \pm 2.60 \mathrm{~s}$, respectively. The average change in the amplitude of the fluorescence signal of the calcium indicator $(\Delta F / F)$ was $67.4 \pm 16.5 \%$. It was interesting to note that intracellular calcium transients in the context of a calcium wave were significantly longer in duration than spontaneous or ATP-induced transients in individual cells, although it is not clear mechanistically why.

We then investigated the population dynamics of calcium wave events in intact networks by plotting the 


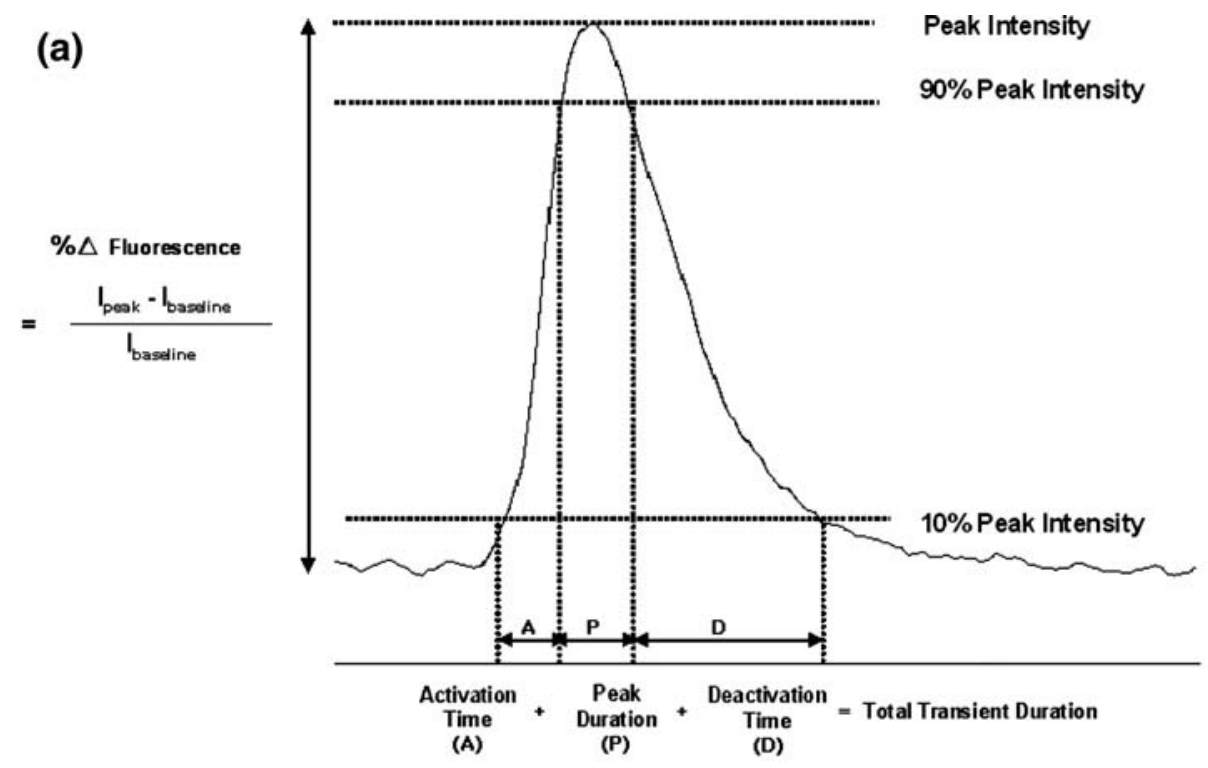

(b)

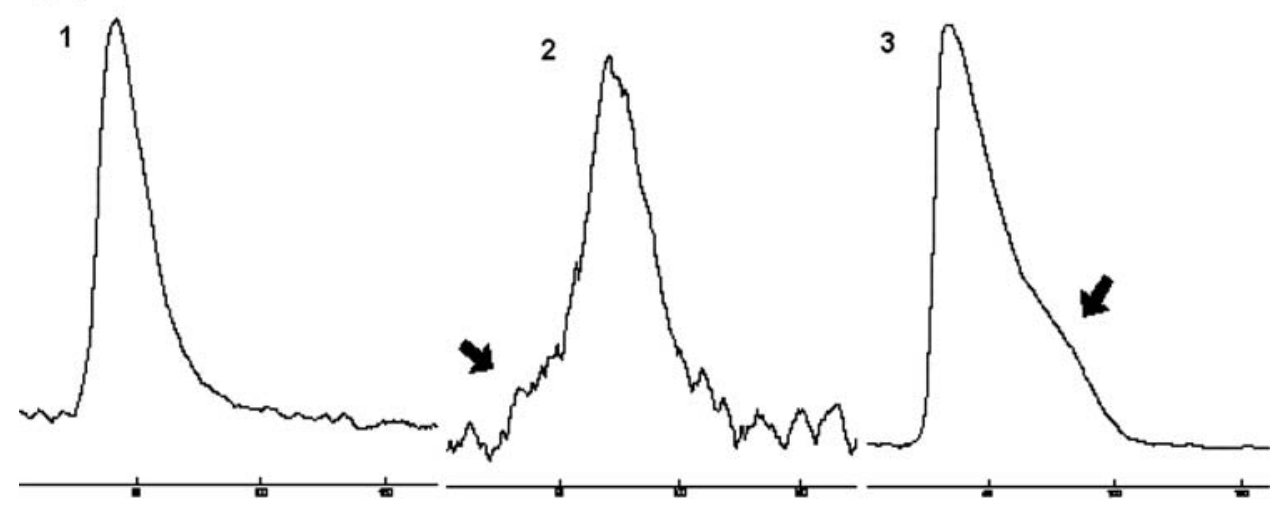

FIGURE 3. (a) Definition of characterization parameters for the analyses of calcium transients. (b) Examples of different observed fluorescent responses (see text for details).

calcium transient parameters described above as a function of radial distance from the stimulation source for all individual cells that contributed to a wave. We were interested in assessing statistical trends associated with changes in individual calcium transients as a function of radial distance. Box plots show spatiotemporal data binned in $50 \mu \mathrm{m}$ radial sections (Fig. 4). The centers of the boxes denote the median value while the upper and lower edges are the 75th and 25th percentiles, respectively. The whiskers show the range of the data and extreme outliers $(+$; defined by $>1.5$ of interquartile distance). The plots suggest that cells located closer to the stimulation site preferentially displayed shorter activation times (Fig. $4 \mathrm{a} ; \sim 2 \mathrm{~s}$ at radius, $r<50 \mu \mathrm{m}$, and $>6 \mathrm{~s}$ at $r>150 \mu \mathrm{m})$, longer deactivation times (Fig. 4b; $\sim 37 \mathrm{~s}$ at $r<50 \mu \mathrm{m}$, and $<25 \mathrm{~s}$ at $r>150 \mu \mathrm{m})$, and larger calcium transient amplitudes (Fig. $4 \mathrm{c} ; \Delta F / F=80 \%$ at $r<50 \mu \mathrm{m}$, and $\Delta F / F<30 \%$ at $r>150 \mu \mathrm{m}$ ). We note that these observations may be due to higher extracellular ATP concentrations near the center of a calcium wave ${ }^{34}$ possibly due to the clustering of the initially activated cells following mechanical stimulation. Furthermore, cells located closer to the stimulation site exhibited a larger range of amplitude changes (i.e., $20-200 \%$ at $r<50 \mu \mathrm{m}$, and $10-75 \%$ at $r>150 \mu \mathrm{m}$ ) and deactivation times (i.e., $10-100 \mathrm{~s}$ at $r<50 \mu \mathrm{m}$, and $15-35 \mathrm{~s}$ at $r>150 \mu \mathrm{m}$ ), while a large range of activation times were observed in cells irrespective of their location (e.g., $0.5-14 \mathrm{~s}$ at $r<50 \mu \mathrm{m}$, and $4.7-17 \mathrm{~s}$ at $r>150 \mu \mathrm{m})$.

Finally, we calculated the velocity of signal propagation between $\mathrm{rMC}-1$ cells, by plotting the radial distance of each activated cell from the stimulation site against its time to activation from the time of simulation. The distance of signal propagation as a function of time followed a logarithmic trend that was fitted well with a power function (Fig. $5, R^{2}=0.86 \pm 0.06$ ). To give a sense of the signaling speed of the wave, the 

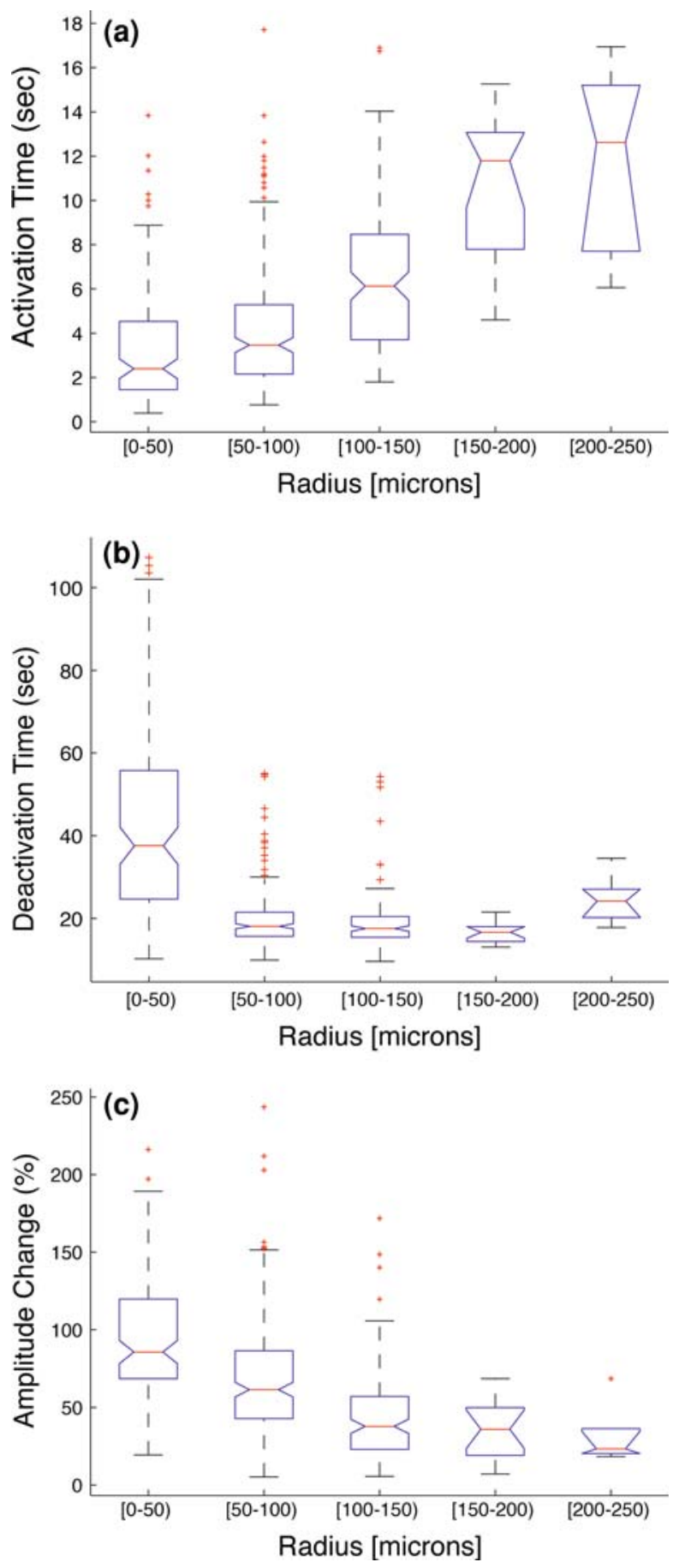

FIGURE 4. Box plots of descriptive calcium transient parameters vs. radial distance from the site of stimulation. The centers of the boxes denote the median value while the upper and lower edges are the 75th and 25th percentiles, respectively. The whiskers show the range of the data, and extreme outliers (defined by $>1.5$ of the interquartile distance) are represented by +. (a) Activation time vs. radial distance. (b) Deactivation time vs. radial distance. (c) Amplitude vs. radial distance.

calculated average propagation velocities at $0.2,0.4$, $0.6,0.8$, and $1.0 \mathrm{~s}$ following stimulations were $23.8 \pm$ $3.7,18.8 \pm 2.2,16.8 \pm 1.5,15.5 \pm 1.0,14.6 \pm 0.8 \mu \mathrm{m} / \mathrm{s}$,

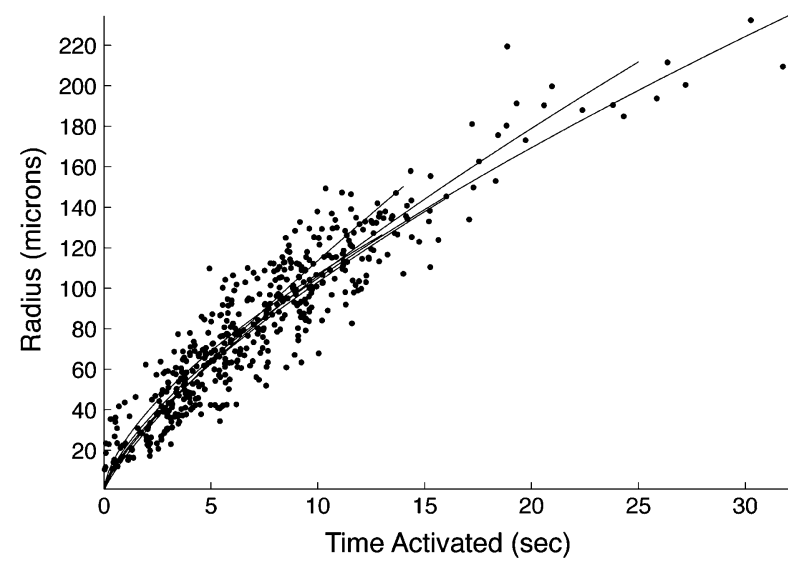

FIGURE 5. Calculation of the velocity of intercellular calcium transient propagation between $\mathrm{rMC}-1$ cells by plotting the distance of activated rMC-1 cells from the stimulation site against its time to activation (defined at $10 \%$ of its measured peak amplitude) in relation to the time of simulation. The resultant plot followed a logarithmic trend that fitted well with a power function to estimate the calcium signaling propagation velocity. Each dataset $(n=5)$ fitted with a power function, $0.77<R^{2}<0.91$.

respectively. The average signaling speed decreased to $10.5 \pm 3.3$ after $5 \mathrm{~s}$, and $7.8 \pm 1.0 \mu \mathrm{m} / \mathrm{s}$ after $10 \mathrm{~s}$. This data suggests that decreases in the signaling speed and response amplitudes along the radial direction of the wave may be associated with mechanisms responsible for the cessation of signal propagation, perhaps by reducing the regenerative component of the calcium wave.

To examine the molecular mechanisms underlying intercellular calcium waves, we pharmacologically perturbed calcium-mediated signaling by applying the purinergic receptor antagonist PPADS ${ }^{24}$ and the gap junction blocker, FFA. ${ }^{41}$ Cultures treated with FFA and PPADS resulted in a $70 \%$ and $86 \%$ decrease in the number of responsive cells, respectively, as compared to control cultures (Fig. 6a). PPADS also affected the duration of individual responses. There was a significant increase in the average duration of intracellular calcium transients in cultures treated with PPADS $(86.71 \pm 46.6 \mathrm{~s}$, mean \pm s.e. $)$ as compared to FFA $(29.1 \pm 3.3 \mathrm{~s}$, mean \pm s.e) or nontreated controls $(31.1 \pm 3.1 \mathrm{~s}$, mean \pm s.e.; Fig. $6 \mathrm{~b})$. These results suggest that the underlying molecular mechanisms responsible for intercellular calcium waves in rMC-1 cells are similar to those described for Müller cells and astrocytes. ${ }^{34}$ Finally, we examined the role of ATP as the extracellular signaling factor in by using the ATPase apyrase at $50 \mathrm{U} / \mathrm{mL}$. Apyrase completely blocked the propagation of calcium transients from initially activated cells to neighboring cells. Application of apyrase at $10 \mathrm{U} / \mathrm{mL}$ also reduced calcium transient propagation to neighboring cells, although some responses were sometimes seen to travel to 

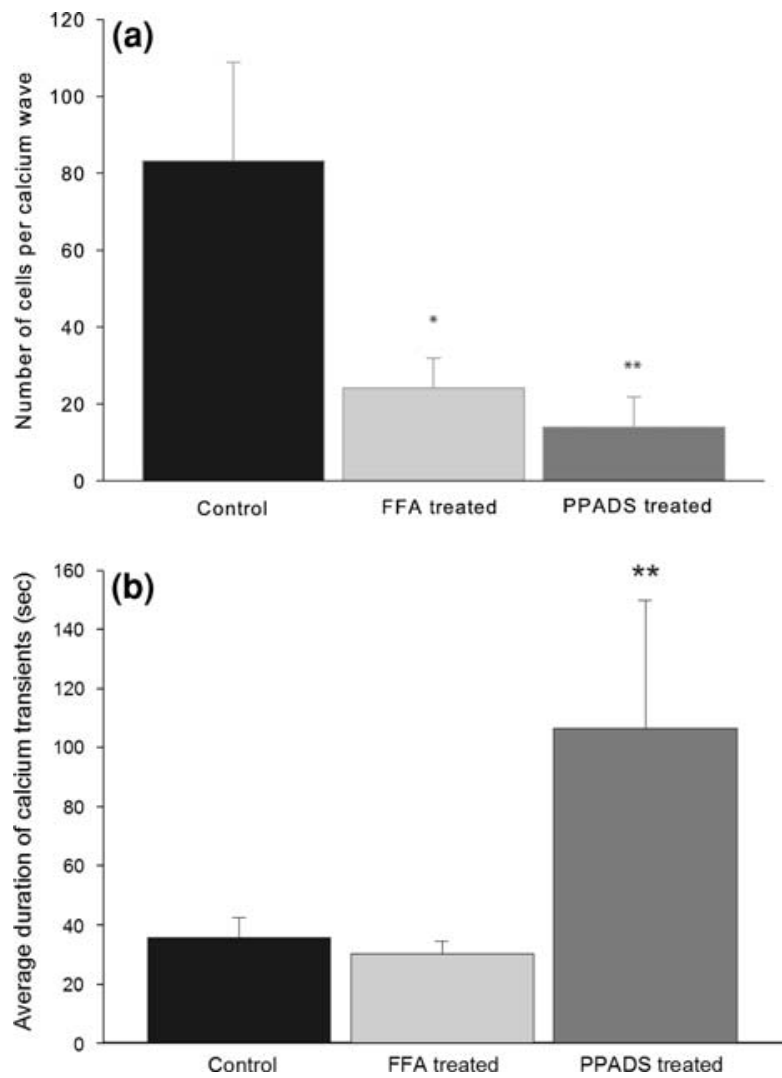

FIGURE 6. FFA-treated and PPADS-treated rMC-1 cultures blocked $\mathrm{IP}_{3^{-}}$and ATP-mediated calcium signaling, respectively. (a) Average number of activated cells per calcium wave. ${ }^{*} p<0.01, n=17$; ${ }^{* \star} p<0.01, n=12$. (b) Average duration of the calcium transients per calcium wave. ${ }^{* *} p<0.01, n=12$.

adjacent cells in immediate cell-cell contact. These results provided further evidence for the involvement of ATP in the molecular mechanism underlying intercellular calcium waves in $\mathrm{rMC}-1$ cells.

\section{DISCUSSION}

We introduced and characterized the dynamics of an in vitro model for studying intracellular and intercellular calcium signaling using the rMC-1 cell line derived from primary rat Müller cells. ${ }^{46}$ Although in vitro systems are simplified representations of physiological conditions, culture systems provide an opportunity to manipulate and investigate molecular and cellular processes in isolation. If the fundamental molecular mechanisms under investigation in the in vitro system are conserved with respect to known physiological processes, then the former provides an opportunity to study elements of these processes at a fundamental level under controlled experimental conditions. The molecular mechanisms that underlie calcium signaling in rMC-1 cells and the dynamics of intracellular calcium transients and intercellular calcium waves are similar to those reported for primary Müller cells and in situ retinal preparations, and thereby provide a molecular model of calcium signaling in Müller cells.

Immunocytochemically, rMC-1 cells exhibited low baseline levels of GFAP, a specific marker for astrocytic and related macroglial cells, ${ }^{13,54}$ similar to nonreactive Müller cells. In addition, they showed positive expression for $\mathrm{P}_{2} \mathrm{Y}_{1} \mathrm{R}$, a G-protein-coupled metabotropic purinergic receptor involved in calcium mobilization from intracellular stores, ${ }^{23,29,55}$ as well as for the $\mathrm{P} 2 \mathrm{X}_{7}$ ionotropic purinergic receptor and connexin 43, which have been respectively shown to augment cytosolic calcium via influx of extracellular calcium in response to $\mathrm{ATP}^{5,39}$ and coordinate intercellular coupling of calcium transients via the formation of gap junction channels. ${ }^{17,51}$ Functionally, rMC-1 cells exhibited intracellular calcium transients that were significantly increased in the presence of ATP, suggesting that these cells express functionally intact purinergic receptors. The effect of ATP was blocked by the application of thapsigargin, which has been previously shown to deplete intracellular calcium stores by specifically inhibiting endoplasmic reticulum calciumATPases. ${ }^{53}$ Our results suggest that ATP-evoked calcium transients in $\mathrm{rMC}-1$ cells were initiated by the release of calcium from intracellular stores similar to that reported for primary Müller cells. ${ }^{31}$ To further elucidate signaling via metabotropic purinergic receptors, we applied $2^{\prime}$-Deoxy- $N^{6}$-methyladenosine- $3^{\prime}$, $5^{\prime}$-bisphosphate (MRS2179), a specific antagonist of the $\mathrm{P} 2 \mathrm{Y}_{1}$ receptor, ${ }^{7,22}$ and showed that it significantly reduced the percentage of signaling cells as well as decreased the number of intracellular calcium transients in the presence of ATP by approximately $50 \%$. The inability of MRS2179 to completely abolish the ATP-induced increase in intracellular calcium transients in the presence of thapsigargin suggests the possibility of additional ATP sensitive metabotropic purinergic receptors subtypes on rMC-1 cells, some of which have been shown to be expressed by primary Müller cells (i.e., $\left.\mathrm{P} 2 \mathrm{Y}_{2}, \mathrm{P}_{2} \mathrm{Y}_{4}, \mathrm{P}_{2} \mathrm{Y}_{6}\right) .{ }^{14,42}$ Application of pyridoxal phosphate-6-azophenyl-2',4'-disulfonic acid (PPADS), a nonspecific $\mathrm{P} 2 \mathrm{Y}$ receptor antagonist that blocks intracellular calcium mobilization by inhibiting $\mathrm{IP}_{3}$ channels ${ }^{57}$ that has been used against $\mathrm{P} 2 \mathrm{Y}_{2}, \quad \mathrm{P} 2 \mathrm{Y}_{4}, \quad \mathrm{P} 2 \mathrm{Y}_{6}, \quad \mathrm{P} 2 \mathrm{Y}_{13}{ }^{8,9,22,28,44,52}$ and $\mathrm{P} 2 \mathrm{Y}_{1}$ receptors. ${ }^{6,27,47}$ was able to completely but reversibly inhibit ATP-stimulated calcium transients. In addition, the results point to the potential involvement of ionotropic purinergic receptors, since the removal of extracellular calcium impeded the ability to these cells to exhibit calcium transients in the presence of ATP. However, additional pharmacological characterization 
is needed to further elucidate a potential ionotropic receptor role in $\mathrm{rMC}-1$ calcium signaling.

The average duration of ATP-induced intracellular calcium transients in rMC-1 cells was within the range of response durations reported for Müller cells in intact retinal preparations, which were measured to be between 2.5 and $6 \mathrm{~s}^{37}$ Surprisingly, along with the increase in the number of intracellular calcium transients in ATP-treated cultures, we also observed a decrease in the average duration and amplitude of calcium elevations in the presence of ATP. The exact mechanism for this is unclear. However, since ATP is a ligand for a number purinergic receptors, it is likely that at elevated extracellular concentrations ATP also activates a number of ionotropic purinergic receptors, such as the $\mathrm{P} 2 \mathrm{X} 7$ receptor we showed to be present on rMC-1 cells (see Fig. 1). This would drastically increase the permeability of the plasma membrane to monovalent and divalent ions, thereby potentially reducing the duration and amplitude of calcium transient responses triggered in individual cells. In addition, it has been suggested that light induces Müller cell calcium transients in the retina via the release of ATP by amacrine and/or retinal ganglion cell neurons. ${ }^{37}$ The exceptional similarity between the duration of calcium transients in ATP-stimulated rMC-1 cells $(3.4 \pm 0.6 \mathrm{~s})$ and that previously reported for Müller cells in light-stimulated intact retinal preparations $(3.84 \pm 0.82 \mathrm{~s})$ further supports that the $\mathrm{rMC}-1$ cell line has retained the principle mechanisms associated with physiological intracellular calcium mobilization and signaling pathways in Müller cells.

Since in situ experiments have also shown the ability of Müller cells to support intercellular calcium waves ${ }^{38}$ and similar events have been observed under conditions that mimic pathology, ${ }^{37}$ we also characterized the dynamics of calcium waves in rMC-1 cultures and tested whether their propagation necessitated an ATP and/or $\mathrm{IP}_{3}$-dependent signaling mechanism. The ability of rMC-1 cell networks to support intercellular calcium waves was demonstrated by the radial propagation of signaling events following a stimulation. Published studies by several groups have implicated extracellular ATP as the primary facilitator of calcium waves in Müller cell networks of healthy and diseased retina. ${ }^{4,29,55,56}$ There is evidence for a similar mechanism in rMC-1 networks based on measurements of calcium waves following the application of the purinergic receptor antagonist PPADS, ${ }^{24}$ which resulted in a significant $(86 \%)$ reduction in the size of the calcium wave as measured based on the number of participating cells. Apyrase, an ATP diphosphohydrolase, inhibited the propagation of calcium transients to secondary cells adjacent to the stimulation site, further implicating a key role of extracellular ATP in intercellular calcium waves in rMC-1 network signaling. However, there were also some differences between $\mathrm{rMC}-1$ cells and Müller cells. Specifically the inhibition of gap junctions using flufenamic acid (FFA), a pharmacological agent that has been shown to reduce $\mathrm{Cx} 32, \mathrm{Cx} 43, \mathrm{Cx} 46$, and $\mathrm{Cx} 40$ currents by $85 \%$ to $95 \%,{ }^{41,49}$ caused a decrease in intercellular calcium signaling by $70 \%$ in rMC-1 cells, which has only been previously reported as the primary mechanism for intercellular calcium waves between retinal astrocytes. ${ }^{34}$ There was also a significant increase in the averaged duration of the intracellular calcium transients in cultures treated with PPADS.

Our calculated value of relative calcium transient amplitudes $(\Delta F / F)$, activation, and deactivation times $(67.4 \pm 16.5 \%, 3.87 \pm 0.62 \mathrm{~s}$, and $18.91 \pm 2.60 \mathrm{~s}$, respectively) for intercellular calcium waves in rMC-1 cell networks were comparable to published results for Müller calcium transients in mechanically stimulated calcium waves in situ. ${ }^{34,38}$ The calculated speed of the initial signal propagation in rMC-1 networks was $23.8 \pm 3.7 \mu \mathrm{m} / \mathrm{s}$ along the radial direction, which was similar to the reported value of $23.1 \pm 6.7 \mu \mathrm{m} / \mathrm{s}$ for mechanically stimulated calcium waves in situ. Combining the results of our kinetics analysis and pharmacological studies, the data suggests that intercellular calcium transient propagation in rMC-1 networks is both qualitatively and quantitatively similar to that reported for Müller cells in in situ retinal preparations.

\section{ACKNOWLEDGMENTS}

This work was funded by NIH grant R01 NS054736-01 and a Walter Coulter Foundation for Biomedical Engineering Early Career Award to G.S.

\section{OPEN ACCESS}

This article is distributed under the terms of the Creative Commons Attribution Noncommercial License which permits any noncommercial use, distribution, and reproduction in any medium, provided the original author(s) and source are credited.

\section{REFERENCES}

${ }^{1}$ Agulhon, C., J. C. Platel, B. Kolomiets, V. Forster, S. Picaud, J. Brocard, P. Faure, and P. Brulet. Bioluminescent imaging of $\mathrm{Ca}^{2+}$ activity reveals spatiotemporal dynamics in glial networks of dark-adapted mouse retina. J. Physiol. 583:945-958, 2007. 
${ }^{2}$ Biedermann, B., A. Bringmann, K. Franze, F. Faude, P. Wiedemann, and A. Reichenbach. GABA(A) receptors in Muller glial cells of the human retina. Glia 46:302-310, 2004.

${ }^{3}$ Bringmann, A., I. Iandiev, T. Pannicke, A. Wurm, E. Buhner, A. Reichenbach, P. Wiedemann, and S. Uhlmann. Porcine Muller glial cells increase expression of $\mathrm{BKCa}$ channels in retinal detachment. Curr. Eye Res. 32:143-151, 2007.

${ }^{4}$ Bringmann, A., T. Pannicke, J. Grosche, M. Francke, P. Wiedemann, S. N. Skatchkov, N. N. Osborne, and A. Reichenbach. Muller cells in the healthy and diseased retina. Prog. Retin. Eye Res. 25:397-424, 2006.

${ }^{5}$ Bringmann, A., T. Pannicke, V. Moll, I. Milenkovic, F. Faude, V. Enzmann, S. Wolf, and A. Reichenbach. Upregulation of $\mathrm{P} 2 \mathrm{X}(7)$ receptor currents in Muller glial cells during proliferative vitreoretinopathy. Invest. Ophthalmol. Vis. Sci. 42:860-867, 2001.

${ }^{6}$ Brown, C. A., S. J. Charlton, and M. R. Boarder. Enhancement of the response to purinergic agonists in P2Y1 transfected $1321 \mathrm{~N} 1$ cells by antagonists suramin and PPADS. Br. J. Pharmacol. 120:1049-1052, 1997.

${ }^{7}$ Camaioni, E., J. L. Boyer, A. Mohanram, T. K. Harden, and K. A. Jacobson. Deoxyadenosine bisphosphate derivatives as potent antagonists at P2Y1 receptors. J. Med. Chem. 41:183-190, 1998.

${ }^{8}$ Charlton, S. J., C. A. Brown, G. A. Weisman, J. T. Turner, L. Erb, and M. R. Boarder. Cloned and transfected P2Y4 receptors: characterization of a suramin and PPADSinsensitive response to UTP. Br. J. Pharmacol. 119:13011303, 1996.

${ }^{9}$ Charlton, S. J., C. A. Brown, G. A. Weisman, J. T. Turner, L. Erb, and M. R. Boarder. PPADS and suramin as antagonists at cloned $\mathrm{P} 2 \mathrm{Y}$ - and $\mathrm{P} 2 \mathrm{U}$-purinoceptors. $\mathrm{Br}$. J. Pharmacol. 118:704-710, 1996.

${ }^{10}$ Du, Y., C. M. Miller, and T. S. Kern. Hyperglycemia increases mitochondrial superoxide in retina and retinal cells. Free Radic. Biol. Med. 35:1491-1499, 2003.

${ }^{11}$ Du, Y., V. P. Sarthy, and T. S. Kern. Interaction between NO and COX pathways in retinal cells exposed to elevated glucose and retina of diabetic rats. Am. J. Physiol. Regul. Integr. Comp. Physiol. 287:R735-741, 2004.

${ }^{12}$ Du, Y., M. A. Smith, C. M. Miller, and T. S. Kern. Diabetes-induced nitrative stress in the retina, and correction by aminoguanidine. J. Neurochem. 80:771-779, 2002.

${ }^{13}$ Eisenfeld, A. J., A. H. Bunt-Milam, and P. V. Sarthy. Muller cell expression of glial fibrillary acidic protein after genetic and experimental photoreceptor degeneration in the rat retina. Invest. Ophthalmol. Vis. Sci. 25:1321-1328, 1984.

${ }^{14}$ Fries, J. E., I. M. Goczalik, T. H. Wheeler-Schilling, K. Kohler, E. Guenther, S. Wolf, P. Wiedemann, A. Bringmann, A. Reichenbach, M. Francke, and T. Pannicke. Identification of $\mathrm{P} 2 \mathrm{Y}$ receptor subtypes in human Muller glial cells by physiology, single cell RTPCR, and immunohistochemistry. Invest. Ophthalmol. Vis. Sci. 46:3000-3007, 2005.

${ }^{15}$ Gustafson, E. C., E. R. Stevens, H. Wolosker, and R. F. Miller. Endogenous D-serine contributes to NMDAreceptor-mediated light-evoked responses in the vertebrate retina. J. Neurophysiol. 98:122-130, 2007.

${ }^{16}$ Hirase, H., L. Qian, P. Bartho, and G. Buzsaki. Calcium dynamics of cortical astrocytic networks in vivo. PLoS Biol. 2:E96, 2004.

${ }^{17}$ Iacobas, D. A., S. O. Suadicani, S. Iacobas, C. Chrisman, M. A. Cohen, D. C. Spray, and E. Scemes. Gap junction and purinergic $\mathrm{P} 2$ receptor proteins as a functional unit: insights from transcriptomics. J. Membr. Biol. 217:83-91, 2007.

${ }^{18}$ Iandiev, I., O. Uckermann, T. Pannicke, A. Wurm, S. Tenckhoff, U. C. Pietsch, A. Reichenbach, P. Wiedemann, A. Bringmann, and S. Uhlmann. Glial cell reactivity in a porcine model of retinal detachment. Invest. Ophthalmol. Vis. Sci. 47:2161-2171, 2006.

${ }^{19}$ Kannan, R., Y. Bao, Y. Wang, V. P. Sarthy, and N. Kaplowitz. Protection from oxidant injury by sodiumdependent GSH uptake in retinal Muller cells. Exp. Eye Res. 68:609-616, 1999.

${ }^{20}$ Keirstead, S. A., and R. F. Miller. Calcium waves in dissociated retinal glial (Muller) cells are evoked by release of calcium from intracellular stores. Glia 14:14-22, 1995.

${ }^{21}$ Kihara, A. H., L. Mantovani de Castro, M. A. Belmonte, C. Y. Yan, A. S. Moriscot, and D. E. Hamassaki. Expression of connexins 36, 43, and 45 during postnatal development of the mouse retina. J. Neurobiol. 66:13971410, 2006.

${ }^{22}$ von Kugelgen, I. Pharmacological profiles of cloned mammalian P2Y-receptor subtypes. Pharmacol. Ther. 110: 415-432, 2006.

${ }^{23} \mathrm{Li}$, Y., L. A. Holtzclaw, and J. T. Russell. Muller cell $\mathrm{Ca}^{2+}$ waves evoked by purinergic receptor agonists in slices of rat retina. J. Neurophysiol. 85:986-994, 2001.

${ }^{24}$ Liu, Y., and M. Wakakura. P1-/P2-purinergic receptors on cultured rabbit retinal Muller cells. Jpn. J. Ophthalmol. 42:33-40, 1998.

${ }^{25}$ Lopez-Colome, A. M., and I. Lee. Pharmacological characterization of inositol-1,4,5,-trisphosphate binding to membranes from retina and retinal cultures. J. Neurosci. Res. 44:149-156, 1996.

${ }^{26}$ Lu, S. C., Y. Bao, Z. Z. Huang, V. P. Sarthy, and R. Kannan. Regulation of gamma-glutamylcysteine synthetase subunit gene expression in retinal Muller cells by oxidative stress. Invest. Ophthalmol. Vis. Sci. 40:1776-1782, 1999.

${ }^{27}$ Marcet, B., V. Chappe, P. Delmas, and B. Verrier. Pharmacological and signaling properties of endogenous P2Y1 receptors in cystic fibrosis transmembrane conductance regulator-expressing Chinese hamster ovary cells. J. Pharmacol. Exp. Ther. 309:533-539, 2004.

${ }^{28}$ Marteau, F., E. Le Poul, D. Communi, C. Labouret, P. Savi, J. M. Boeynaems, and N. S. Gonzalez. Pharmacological characterization of the human P2Y13 receptor. Mol. Pharmacol. 64:104-112, 2003.

${ }^{29}$ Metea, M. R., and E. A. Newman. Calcium signaling in specialized glial cells. Glia 54:650-655, 2006.

${ }^{30}$ Milenkovic, I., M. Weick, P. Wiedemann, A. Reichenbach, and A. Bringmann. P2Y receptor-mediated stimulation of Muller glial cell DNA synthesis: dependence on EGF and PDGF receptor transactivation. Invest. Ophthalmol. Vis. Sci. 44:1211-1220, 2003.

${ }^{31}$ Moll, V., M. Weick, I. Milenkovic, H. Kodal, A. Reichenbach, and A. Bringmann. P2Y receptor-mediated stimulation of Muller glial DNA synthesis. Invest. Ophthalmol. Vis. Sci. 43:766-773, 2002.

${ }^{32}$ Nedergaard, M., A. J. Cooper, and S. A. Goldman. Gap junctions are required for the propagation of spreading depression. J. Neurobiol. 28:433-444, 1995.

${ }^{33}$ Nett, W. J., S. H. Oloff, and K. D. McCarthy. Hippocampal astrocytes in situ exhibit calcium oscillations that occur independent of neuronal activity. J. Neurophysiol. 87:528-537, 2002. 
${ }^{34}$ Newman, E. A. Propagation of intercellular calcium waves in retinal astrocytes and Muller cells. J. Neurosci. 21:22152223, 2001.

${ }^{35}$ Newman, E. A. Glial cell inhibition of neurons by release of ATP. J. Neurosci. 23:1659-1666, 2003.

${ }^{36}$ Newman, E. A. Glial modulation of synaptic transmission in the retina. Glia 47:268-274, 2004.

${ }^{37}$ Newman, E. A. Calcium increases in retinal glial cells evoked by light-induced neuronal activity. J. Neurosci. 25:5502-5510, 2005.

${ }^{38}$ Newman, E. A., and K. R. Zahs. Calcium waves in retinal glial cells. Science 275:844-847, 1997.

${ }^{39}$ Pannicke, T., W. Fischer, B. Biedermann, H. Schadlich, J. Grosche, F. Faude, P. Wiedemann, C. Allgaier, P. Illes, G. Burnstock, and A. Reichenbach. P2X7 receptors in Muller glial cells from the human retina. J. Neurosci. 20:5965-5972, 2000.

${ }^{40}$ Parri, H. R., and V. Crunelli. The role of $\mathrm{Ca}^{2+}$ in the generation of spontaneous astrocytic $\mathrm{Ca}^{2+}$ oscillations. Neuroscience 120:979-992, 2003.

${ }^{41}$ Rana, S., and R. Dringen. Gap junction hemichannelmediated release of glutathione from cultured rat astrocytes. Neurosci. Lett. 415:45-48, 2007.

${ }^{42}$ Reifel Saltzberg, J. M., K. A. Garvey, and S. A. Keirstead. Pharmacological characterization of $\mathrm{P} 2 \mathrm{Y}$ receptor subtypes on isolated tiger salamander Muller cells. Glia 42:149-159, 2003.

${ }^{43}$ Ribelayga, C., and S. C. Mangel. A circadian clock and light/dark adaptation differentially regulate adenosine in the mammalian retina. J. Neurosci. 25:215-222, 2005.

${ }^{44}$ Robaye, B., J. M. Boeynaems, and D. Communi. Slow desensitization of the human P2Y6 receptor. Eur. J. Pharmacol. 329:231-236, 1997.

${ }^{45}$ Rogers, K. L., J. Stinnakre, C. Agulhon, D. Jublot, S. L. Shorte, E. J. Kremer, and P. Brulet. Visualization of local $\mathrm{Ca}^{2+}$ dynamics with genetically encoded bioluminescent reporters. Eur. J. Neurosci. 21:597-610, 2005.

${ }^{46}$ Sarthy, V. P., S. J. Brodjian, K. Dutt, B. N. Kennedy, R. P. French, and J. W. Crabb. Establishment and characterization of a retinal Muller cell line. Invest. Ophthalmol. Vis. Sci. 39:212-216, 1998.

${ }^{47}$ Schachter, J. B., Q. Li, J. L. Boyer, R. A. Nicholas, and T. K. Harden. Second messenger cascade specificity and pharmacological selectivity of the human P2Y1-purinoceptor. Br. J. Pharmacol. 118:167-173, 1996.

${ }^{48}$ Shelton, M. D., T. S. Kern, and J. J. Mieyal. Glutaredoxin regulates nuclear factor kappa-B and intercellular adhesion molecule in Muller cells: model of diabetic retinopathy. J. Biol. Chem. 282:12467-12474, 2007.
${ }^{49}$ Srinivas, M., and D. C. Spray. Closure of gap junction channels by arylaminobenzoates. Mol. Pharmacol. 63: 1389-1397, 2003.

${ }^{50}$ Stevens, E. R., M. Esguerra, P. M. Kim, E. A. Newman, S. H. Snyder, K. R. Zahs, and R. F. Miller. D-serine and serine racemase are present in the vertebrate retina and contribute to the physiological activation of NMDA receptors. Proc. Natl. Acad. Sci. USA 100:6789-6794, 2003.

${ }^{51}$ Suadicani, S. O., C. E. Flores, M. Urban-Maldonado, M. Beelitz, and E. Scemes. Gap junction channels coordinate the propagation of intercellular $\mathrm{Ca}^{2+}$ signals generated by P2Y receptor activation. Glia 48:217-229, 2004.

${ }^{52}$ Suarez-Huerta, N., V. Pouillon, J. Boeynaems, and B. Robaye. Molecular cloning and characterization of the mouse P2Y4 nucleotide receptor. Eur. J. Pharmacol. 416:197-202, 2001.

${ }^{53}$ Thastrup, O., P. J. Cullen, B. K. Drobak, M. R. Hanley, and A. P. Dawson. Thapsigargin, a tumor promoter, discharges intracellular $\mathrm{Ca}^{2+}$ stores by specific inhibition of the endoplasmic reticulum $\mathrm{Ca}^{2(+)}$-ATPase. Proc. Natl. Acad. Sci. USA 87:2466-2470, 1990.

${ }^{54}$ Trimmer, P. A., P. J. Reier, T. H. Oh, and L. F. Eng. An ultrastructural and immunocytochemical study of astrocytic differentiation in vitro: changes in the composition and distribution of the cellular cytoskeleton. J. Neuroimmunol. 2:235-260, 1982.

${ }^{55}$ Uckermann, O., J. Grosche, A. Reichenbach, and A. Bringmann. ATP-evoked calcium responses of radial glial (Muller) cells in the postnatal rabbit retina. J. Neurosci. Res. 70:209-218, 2002.

${ }^{56}$ Uckermann, O., S. Uhlmann, M. Weick, T. Pannicke, M. Francke, A. Reichenbach, P. Wiedemann, and A. Bringmann. Upregulation of purinergic P2Y receptormediated calcium responses in glial cells during experimental detachment of the rabbit retina. Neurosci. Lett. 338:131-134, 2003.

${ }^{57}$ Vigne, P., P. Pacaud, V. Urbach, E. Feolde, J. P. Breittmayer, and C. Frelin. The effect of PPADS as an antagonist of inositol $(1,4,5)$ trisphosphate induced intracellular calcium mobilization. Br. J. Pharmacol. 119:360364, 1996

${ }^{58}$ Weick, M., P. Wiedemann, A. Reichenbach, and A. Bringmann. Resensitization of $\mathrm{P} 2 \mathrm{Y}$ receptors by growth factor-mediated activation of the phosphatidylinositol-3 kinase in retinal glial cells. Invest. Ophthalmol. Vis. Sci. 46:1525-1532, 2005.

${ }^{59}$ Zahs, K. R., P. Kofuji, C. Meier, and R. Dermietzel. Connexin immunoreactivity in glial cells of the rat retina. J. Comp. Neurol. 455:531-546, 2003. 